\title{
Correction to: Sustainable Development and the Legal Regulation of Forced Migration in Russia
}

\author{
Dmitry V. Ivanov (D) and Nikita Yu. Molchakov
}

\section{Correction to:}

Chapter 24 in: A. O. Inshakova and E. E. Frolova (eds.), Smart Technologies for the Digitisation of Industry:

Entrepreneurial Environment, Smart Innovation, Systems and Technologies 254, https://doi.org/10.1007/978-981-16-4621-8_24

In the original version of the book, the misspelt co-author name "Nikita Yu. Molchkov" has been changed to read as "Nikita Yu. Molchakov" in Chapter "Sustainable Development and the Legal Regulation of Forced Migration in Russia". The erratum chapter and the book have been updated with the change. 